\title{
Effect of Adding Various Chemicals to Wood Previous to Distillation ${ }^{2}$
}

\author{
By L. F. Hawley
}

Forest Products Lagoratory, Madison, Wisconsin

This investigation is a continuation of Palmer's work on "The Effect of Catalyzers on the Yield of Products in the Destructive Distillation of Birch."'2 A new title has been chosen since it is not wished to imply that the action in all cases is truly catalytic and since it is not intended to limit the work to one species of wood.

Aside from Palmer's work, in which the wood was treated with phosphoric acid, the only publication on the subject is a recent short note ${ }^{3}$ without details, in which it is stated that when wood is distilled in the presence of three or more parts of lime the acid yield (in form of acetone) is greatly increased. Nothing is said about an effect on the yields of alcohol.

Different distillation methods from those used by Palmer were used in the present study in order to develop a simpler process and one which could be used for maintaining an even mixture of sawdust with insoluble materials such as lime. The sawdust was mixed with the solid material if an insoluble chemical was used or was saturated with a solution of the chemical, then dried if necessary, and pressed into briquets $2 \mathrm{in}$. in diameter and about $1 \mathrm{in}$. in thickness. These briquets were distilled in a tube furnace under sufficient mechanical pressure to prevent them from falling apart, and the products were collected and analyzed in the usual manner. This general method of distillation had been used in a previous investigation and was found to be simple and satisfactory.

\section{Silver Maple Sawdust}

PHOSPHORIC ACID-The results of several trials with phosphoric acid are shown in Table I. With wood treated with three different concentrations of the acid $(0.5,1$, and 1.5$)$, there was a slight decrease in the yield of alcohol and a slight increase in the yield of acid as compared with untreated wood, although the increase and decrease did not follow a regular order according to the amount of acid used. The increase in yield of acid was not sufficient to make phosphoric acid treatment a promising process, especially since the alcohol was slightly decreased. The only distillation of wood treated with phosphoric acid in which a large yield of acid was obtained reported by Palmer was made by distillation under high pressure, a condition which could not be readily obtained in commercial-sized apparatus. Apparently, the use of phosphoric acid under ordinary conditions of pressure is not promising.

LIME-Lime was tested, mixed with the sawdust both in the form of dry lime and milk of lime. The only noticeable effect of small percentages of lime was a decrease in the amount of acetic acid. With larger proportions of lime, as shown in Table I, there was a noticeable increase in the alcohol yield. This alcohol yield was determined by the specific gravity of a fraction of the distillate after redistillation with alkali and acid. It was, therefore, not a determination of pure methyl alcohol, but included also acetone and other materials with low gravities. Contrary to expectation, this increase in total alcohol, constituents was not due to an increase in the acetone content. Acetone determinations were made in all cases with the results varying only between 0.01 and 0.05 per cent, which is not sufficient to require any further discussion. This corresponds with Bassett's state-

1 Presented before the Section of Cellulose Chemistry at the 61st Meeting of the American Chemical Society, Rochester, N. Y., April 26 to 29 1921.

2 ThIS JoURNAL, 10 (1918), 264.

- H. P. Bassett, Chem. Met. Eng, 20 (1919), 190.

1 Hawley, Tars Journal, 13 (1921), 301.

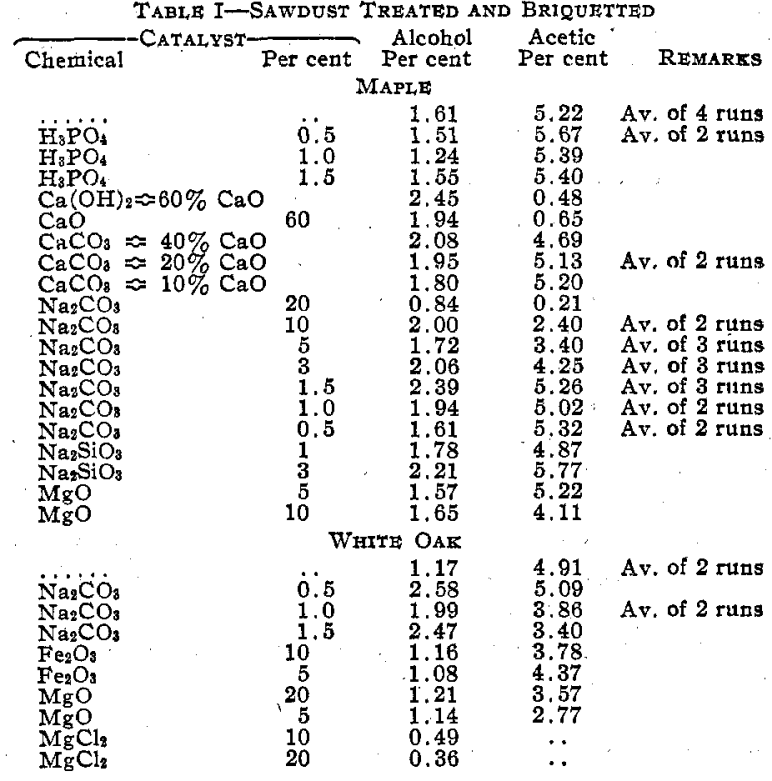

ment that large acetone yields were obtained only when three times as much lime as wood was used.

The results obtained with lime are very interesting in the large yields of wood alcohol obtained, but the greatly decreased vields of acid make the method unpromising.

CALCIUM CARBONATE-Several runs were made with calcium carbonate instead of calcium hydroxide in an attempt to maintain the high alcohol yields without decreasing the acid. With large amounts of calcium carbonate high yields of alcohol were obtained with only slightly decreased acid yields. With smaller amounts of carbonate the yields of acid were about normal while the alcohol yields were still increased to some extent. However, the amount of carbonate required to obtain satisfactory results was so great that the value of the charcoal was seriously diminished. Only in cases where the charcoal was not considered of much value or where it might be used as fuel in the near vicinity of the plant might this process be promising.

It might be supposed that the lime or carbonate was partly transformed into calcium acetate during the first part of the distillation and, if the temperature was not great enough to decompose it, a residue of calcium acetate might be left with: the charcoal. This was tested out in several cases, but not. more than a slight trace of calcium acetate was found in the charcoal.

SODIUM CARBONATE-The first few distillations with large amounts of sodium carbonate material were unsatisfactory. The distillations were rather violent at times and low yields: of both alcohol and acid were obtained. This is shown in: Table I, where the use of 20 per cent sodium carbonate gives very unpromising results. With 10 per cent, however, a slightly increased yield of alcohol was obtained, although the acid was still low. The amount of carbonate was gradually decreased, until with 1.5 per cent a large increase in alcohol was obtained without any decrease of acid. Smaller amounts of carbonate were not so satisfactory, although even with 1 per cent a considerable increase in alcohol was obtained. These effects of sodium carbonate on the reaction of the decomposition of wood by heat are difficult to explain, especially the frequent increase of acid yields due to an alkaline treatment. In several cases the charcoal was 
leached and the soluble salt examined. More than 20 per cent of the sodium was never found in the form of acetate, and this acetate never amounted to more than 0.3 per cent of acetic acid on the weight of the wood distilled.

SODIUM SILICATE-Sodium silicate acts as a mild alkali similar to sodium carbonate. Similar results were obtained, although slightly larger amounts of silicate were apperently required to give the same increase in yields.

MAGNESIUM OXIDE--Magnesium oxide was used in concentrations of 5 and 10 per cent without appreciable increases in yields of either alcohol or acid.

\section{White OAK Sawdust}

All of these distillations were made with the same lot of sawdust from silver maple. The rest of the results reported in Table I were on white oak sawdust, and in comparing these with previous results it should be noted that the blank runs with oak where no chemical was used gave considerably lower yields, especially of alcohol. Sodium carbonate seems to have an even greater effect on the alcohol yields of oak than on those of maple. With as little as 0.5 per cent of sodium carbonate, one distillation gave double the yield of alcohol and slightly increased yields of acetate. The results obtained with 1 and 1.5 per cent were not so satisfactory, especially on account of the small acid yields, but high alcohol yields were obtained in both cases.

Iron oxide mixed with the sawdust in 5 and 10 per cent proportions did not show any promising results. The same was found in connection with the use of magnesium oxide and magnesium chloride. In the case of the latter chemical, high acid yields were recorded but tests showed that there was chloride present in this acid.

These results obtained with briquetted sawdust indicated that sodium carbonate was the most favorable chemical for further tests, both on account of its cheapness and its effect on the yields of alcohol. Further experiments were, therefore, carried out with this chemical upon wood in larger sizes.

\section{Tests on Blocks of WOOD}

Blocks of white oak and maple wood $6 \mathrm{in}$. long were treated with a solution of sodium carbonate under $100 \mathrm{lbs}$. pressure so that a fairly uniform penetration of the solution was obtained. In the case of the maple blocks the distribution of the solution was especially complete. In the oak blocks, however, it was only the sapwood where penetration to the center was obtained, the heartwood showing only a slight penetration of perhaps $0.5 \mathrm{in}$. The blocks were distilled in the oiljacketed retort in which previous wood distillation experiments have been made, and the results were compared with some of the same blocks which were distilled without previous chemical treatment. Table II shows the results of these

Table II-Blocks of Wood Treated with Sodium Carbonate

$\begin{array}{ll} & \\ \begin{array}{cl}\text { Per } \\ \text { cent }\end{array} & \\ & \\ 0.52 & \text { Pressure } \\ 1.03 & \text { Pressure } \\ 1.26 & \text { Soaked } \\ & \\ 0.68 & \text { Pressure } \\ 1.12 & \text { Pressure } \\ 3.15 & \text { Soaked }\end{array}$

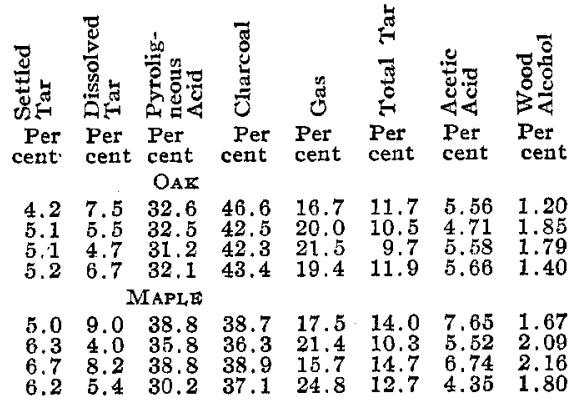

distillations. In the case of the oak blocks a 50 per cent increase in wood alcohol was obtained with no decrease in the acetic acid in one series of runs (with 1.03 per cent carbonate), with a slight decrease in the other series (with 0.52 per cent carbonate). It is difficult to account for this decrease in acid where a smaller amount of sodium carbonate was used, but since all of the results given in the table were obtained from average figures on two distillations the results cannot be very inaccurate. In the case of the maple blocks there was a pronounced increase of alcohol (with 0.68 per cent and with 1.12 per cent carbonate), but in both series of runs the acetic acid was very considerably decreased. The question of the decrease in acid yields needs to be studied further since the results were erratic. In some distillations a slight increase appeared, while in other runs there was a very considerable decrease in acid.

In order to show the effect of the sodium carbonate when not well distributed throughout the wood, runs were made on both oak and maple blocks which had simply been soaked in a solution of sodium carbonate without the application of pressure. The penetration was very slight at the ends of the blocks, and on the sides there was hardly more than a wet surface. The results of the distillation show that it is necessary to have all parts of the wood in contact with the chemical at the time of distillation in order to obtain the best results. Although in all cases there was a slight increase in alcohol from the soaked blocks, this increase was much less than in the case of pressure treated blocks or of briquetted sawdust.

The complete data on these runs with blocks are given in Table II, but little information of value can be obtained from the figures on the products other than acetic acid and wood alcohol. A variation in the relative amounts of pyroligneous acid, charcoal, and gas can be obtained by variation in the maximum temperature to which the charcoal is heated. Since this maximum temperature cannot be readily controlled in the apparatus used, the variations in these three products cannot be controlled and the percentage yield cannot be taken as an indication of the effect of the sodium carbonate.

\section{Discussion of Application}

It can be seen from these results that sodium carbonate previous to distillation can best be used in connection with processes for the distillation of sawdust. Since there are no processes of this kind in operation it has been impossible to test out the application of this principle on a commercial scale. It is very likely, however, that some sawdust distillation plants may be in operation in the near future.

It would probably be impossible to treat the ordinary distillation wood with sodium carbonate solution in such a way as to obtain much benefit therefrom. Most wood is distilled in 4-ft. lengths, and even with a pressure treatment it would be difficult to obtain an even distribution of the carbonate solution throughout such large sticks of wood. There are, however, a few commercial wood distillation plants which are using blocks because they are better suited for their artificial drying process than the ordinary 4-ft. sticks of wood. It is possible that these plants could submit their blocks to a pressure treatment with sodium carbonate solution. before the wood goes to the driers and obtain thereby sufficiently increased yields of alcohol to make the process profitable. It is very likely that the value of the wood alcohol from wood distillation will be much greater than that of the acetic acid, so that any slight decrease in acid yield will not be a very great detriment to this process. If the commercial value of acetic acid products continues as low as it is at the present time, it is also possible that wood distillation plants will not attempt to recover acetic acid but will distil the alcohol from the pyroligneous acid and let the rest of the products go to waste. In this case the slightly diminished yields of acict would be of no disadvantage.

Other chemicals are being tested, and the effect of the distribution of the chemical is being determined. It is also hoped that an early opportunity will be afforded for trying out on a commercial scale the distillation of wood treated with sodium carbonate. 